\title{
High conductive zones beneath mountain range of Taiwan imaged by MT exploration and its tectonics interpretation
}

\author{
Chih-Wen Chiang ${ }^{1}$, Chien-Chih Chen ${ }^{1}$, Chow-Son Chen ${ }^{1}$, Edward Bertrand ${ }^{2}$, \\ and Martyn Unsworth ${ }^{2}$ \\ ${ }^{1}$ Institute of Geophysics, National Central University, Chungli, 32001, Taiwan. \\ ${ }^{2}$ Department of Physics, University of Alberta, Edmonton, Alberta, T6G 2J1, Canada.
}

\begin{abstract}
The Taiwan orogen has formed as a result of the arc-continent collision between the Eurasian continental margin and the Luzon island arc over the last 5 million years and is the type example of an arc-continent collision. The tectonic processes at work beneath Taiwan are still debated, and the available data have been interpreted with both thin-skinned and thick-skinned models. In 2004, the Taiwan Integrated Geodynamical Research (TAIGER) project began a systematic investigation of the crustal and upper mantle structure beneath Taiwan. TAIGER magnetotelluric (MT) data from Central Taiwan favour a thick-skinned model for that region. The Taiwan orogen becomes younger to the south, so the earlier stages of collision were investigated with a $100-\mathrm{km}-$ long MT profile in southern Taiwan. Data were recorded at $15 \mathrm{MT}$ sites and tensor decomposition and two-dimensional inversion were applied to the MT data. The shallow electrical structure is in good agreement with surface geology. The deeper structure shows a major conductor in the mid-crust that can be explained by fluid content of $0.4-1.4 \%$. A similar feature was observed in Central Taiwan, but with a higher fluid content. The conductor in Southern Taiwan extends to lower crustal depths and is likely caused by fluids generated by metamorphic reactions in a thickened crust. Together the Central and Southern Taiwan MT profiles favor a model with thick skinned deformation.
\end{abstract}

\section{INTRODUCTION}

The island of Taiwan was created by oceaniccontinental collision between the Luzon volcanic arc along the western margin of the Philippine Sea plate and the passive continental margin of southeastern China 5 Ma ago (Suppe, 1981; Ho, 1986). At this location, the Philippine Sea plate is subducting northward under the Eurasian plate, and a portion of the Eurasia Plate is subducting eastward under the oceanic plate (Tasi, 1989; Seno, 1993; Kao, 2000). This is a young active orogeny and unique natural laboratory for studying arc-continental collisional processes around the world. Since the unique collisional tectonics issues had been proposed, various physics and simulation models have been suggested (e.g. Suppe, 1981; Wu et al., 1997; Wang, 2006; Wu et al., 2007).

However, scientists are mainly debating the tectonics setting beneath Taiwan, which can be interpreted as a thin-skinned tectonics model (Suppe, 1981) or lithospheric collision model ( $\mathrm{Wu}$ et al., 1997) and its plate boundary. Although no deep crustal information was available when the thin-skinned model has been suggested, and also limited resolution of deep structure for the lithospheric collision model due to lacked of telseismic data. However, to fully understand the tectonic processes associated with the collision and compared with previous researches, it is necessary to study other parts of the orogenesis such as deep structure of Taiwan.

Since 2007, the TAiwan Integrated GEodynamics Research project (TAIGER) has been dedicated to investigating the existence of tectonics issues in Taiwan. This project combines seismology, magnetotellurics (MT), geology, and other fields of study. The project is mainly supporting by National Science Council (NSC) of Taiwan, and National Science Foundation (NSF) of Unite State. There are five national universities and Academia Sinica at Taiwan; six institutes from U.S., as well as one from a Canadian university ( $\mathrm{Wu}, 2007)$. In the MT study, National Central University of Taiwan and University of Alberta, Canada are cooperating to collect data. In this paper, we will describe more details of the electrical model and its tectonic implications beneath southern Taiwan.

\section{MT DATA COLLECTION AND ANALYSIS}

For southern transect, we used two systems to record MT data: five-component commercial V5-2000 wideband systems designed by Phoenix Geophysics Ltd. for shallow probing, and five-component NIMS recording systems designed by Narod Geophysics Ltd. for deeper penetration. The time series data acquired at each site was calculated using two robust statistics algorithms (Egbert and Booker, 1986; Jones, 1989) with remote-reference (Gamble et al., 1979) to estimate the response of transfer functions over $0.0026 \sim 10,000$ seconds from variations in the Earth's natural electromagnetic field. For doing the remote reference technique, remote station was deployed on Penghu island approximately $50 \mathrm{~km}$ away from Taiwan (Figure 1). Long periods MT data at Central and north transect has only been used.

Before MT data can be converted to subsurface resisitivty models, dimensionality analysis is required to understand and determine its in full $3 \mathrm{D}$ environment. A $2 \mathrm{D}$ analysis assumption of the real case is simpler than 
3D analysis (Unsworth et al., 2007). Therefore, the extended GB technique (McNeice and Jones, 2001) was applied for all the data sets to reduced subsurface electric distortion. The dominant electric strike was well-defined at $\mathrm{N} 45^{\circ} \mathrm{E}, \mathrm{N} 37^{\circ} \mathrm{E}$ and $\mathrm{N} 29^{\circ} \mathrm{E}$ from north to south respectively, with multi-stations parallel to the various tectonic setting for the period range from 13 to 7,447 seconds.

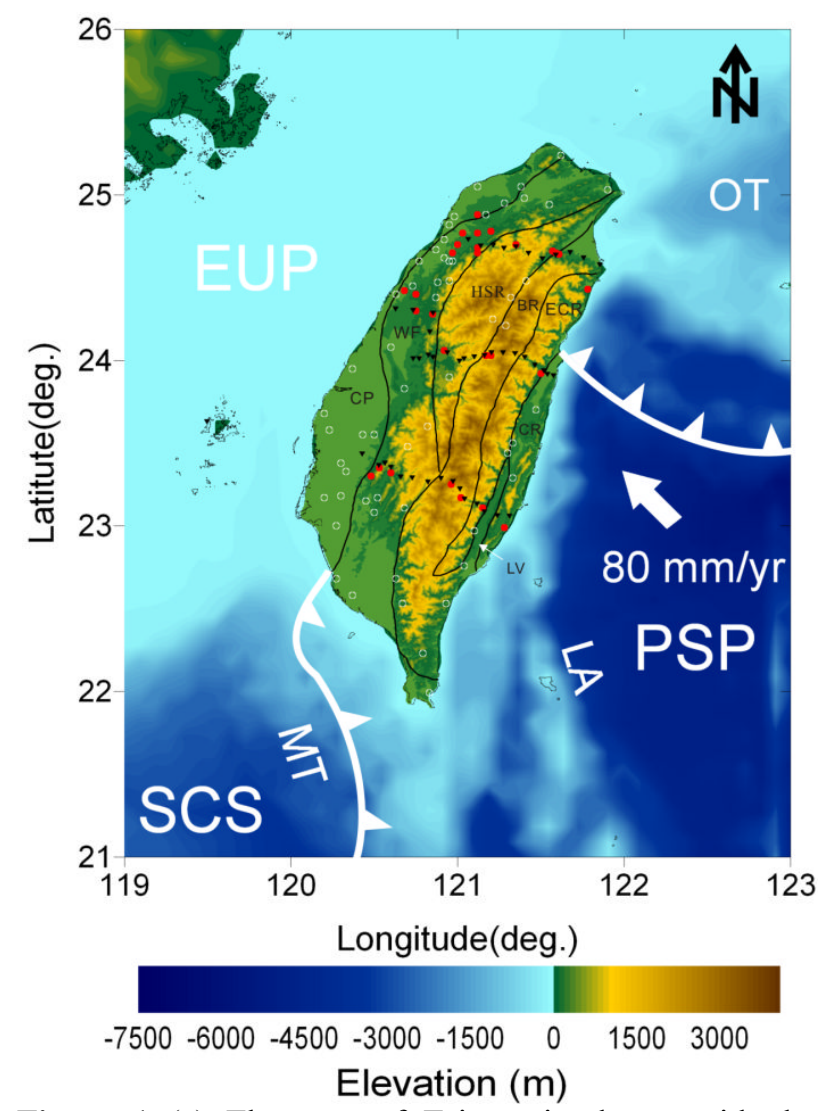

Figure 1 (a) The map of Taiwan is shown with the topography and simplified tectonostratigraphic boundaries (Ho, 1986), I: Costal Plane (CP), II: Western Foothills (WF), III: Hsuehshan Range (HR), IV: Backbone Range (BR), V: Eastern Central Range (ECR), VI: Costal Range (CR), VII: Longitudinal Valley (LV). The MT station is shown in block dots, while red dots are indicated heat flow measurements, close to the MT stations within profiles.

Converting the apparent resistivity and phase data variations to depth information requires an inversion algorithm. Therefore, we applied NLCG method (Rodi and Makie, 2001) to convert the MT data into apparent resistivity, phase curves and projected with induction vectors. The conductivity of seawater was fixed with 0.3 ohm-m for both the Taiwan Strait and Pacific Ocean beside Taiwan according to the bathymetry. ). The data misfit is shown in figure 2 .

\section{RESULT AND INTERPRETATION}

Figure 3 shows the preferred inversion model overlaid with selected earthquake hypocenters
$(\mathrm{Mw}>=3.0)$ from Central Weather Bureau, CWB located within $15 \mathrm{~km}$ of the MT profile. At shallow depths $(0-10 \mathrm{~km})$, the resistivity progressively increases from west to east across Taiwan, which is as expected for the change in lithology from sedimentary rocks $(\mathrm{CP})$, to meta-sedimentary rocks (WF and HR), to higher-grade metamorphic rocks (BR and ECR). Three significant conductivity anomalies are observed in the shallow crust $(\mathrm{C} 1, \mathrm{C} 2$ and $\mathrm{C} 3$ ) and a fourth is located in the mid-crust (C4).
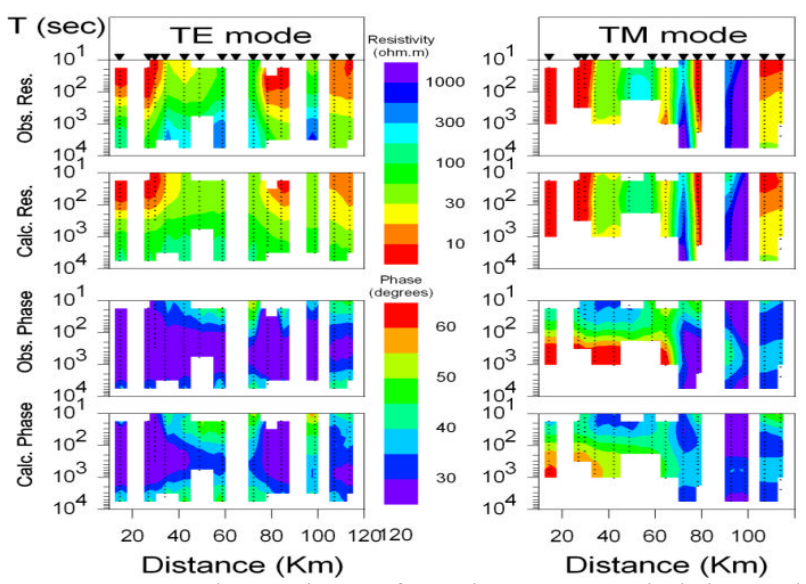

Figure 2 Pseudo-sections of southern MT resistivity and phase model response for both TE and TM polarization modes and tipper, here the currents flow alone (TE) and cross (TM) the geological strike.

C1 is spatially associated with the Quaternary sedimentary rocks of the Coastal Plain in southwestern Taiwan and coincides with a zone of low seismic velocity (Kim, et al., 2005; Wu et al., 2007). High porosity sedimentary rocks, saturated with interconnected fluids can account for this conductive $\mathrm{C} 1$ anomaly. Higher resistivities are observed beneath the Western Foothills and indicate the lower porosity of Neogene sedimentary rocks with low-grade metamorphism. The geothermal gradient in the Central Range is high (Wang et al., 1994; Lin, 2002) and the region has numerous geothermal phenomena (Ho, 1999). Relatively high heat flow of $350 \mathrm{~mW} / \mathrm{m}^{2}$ is observed close to $\mathrm{C} 2$ (Figure. 3b). Thus, C2 may be related to the circulation of geothermal fluids in this area where the fractures associated with the Central Range Fault (CERF) between the BR and ECR could give the necessary permeability. Further east, feature $\mathrm{C} 3$ is located within the Coastal Range and may be related to a typical marine mélange with heterogeneous rock materials consisting of a sheared argillaceous matrix mixed thoroughly with native and exotic tectonic fragments (Hsu, 1956; 1976; Ho, 1999). C3 is also coincident with the low $\mathrm{V}_{\mathrm{p}}$ and high $\mathrm{V}_{\mathrm{p}} / \mathrm{V}_{\mathrm{s}}$ zone reported by $\mathrm{Wu}$ et al., 
(2007). This phenomenon indicates that the conductive anomaly may be related to a fractured formation and fluid-filled seismicity zone.

The most important feature shown in the inversion model is the conductive anomaly $\mathrm{C} 4$ located beneath the Central Ranges in the mid-crust with the top at a depth of $15 \mathrm{~km}$ (Figure. 3c). This conductor is coincident with a zone of low shear-wave velocity observed beneath the central ranges (Kim, et al., 2005; Wu et al., 2007). The resistivity of $\mathrm{C} 4$ is an order of magnitude lower than the surrounding crust at the same range of depths. The most likely explanation of the low resistivity is saline aqueous fluids. The electrical resistivity of brine depends on the salinity, pressure and temperature (Sourirajan and Kennedy, 1962; Quist and Marshall 1968). The resistivity of C4 is $30 \Omega \mathrm{m}$ and this can be explained with fluid content of $0.4-1.4 \%$ if the fluid resistivity is in the range 0.01-0.05 $\Omega \mathrm{m}$ (Nesbitt, 1993) and the cementation factor value of $m=1.5$ in Archie's Law. The existence of deep crustal fluids in Southern Taiwan is significant because fluids may play an important role in crustal deformation in active orogens (e.g. Chen and Chen, 1998; Soyer and Unsworth, 2006). The elevated fluid content and high geothermal gradient shown in Figure $3 b$, has been related to uplift and thickening of the crust in the Central Range (Lin 2002; Wang and Hung, 2002).

\section{CONCLUSIONS}

This paper describes the analysis and interpretation of joint long-period and broad-band MT data collected as part of the TAIGER project in southern Taiwan. These MT data have been carefully analyzed and shown to exhibit an overall 2D nature. 3D forward modeling suggests that the surrounding sweater does not contaminate resolution of features observed in the $2 \mathrm{D}$ inversion models at periods less than 1000 seconds. These conductive anomalies observed in the MT model are interpreted to be associated with interconnected fluids within the crust. The shallow electrical structures correlate well with geological units mapped at the surface. The resistivity gradually changes from lower to higher resistivities from west to east as the lithology changes from sedimentary to metamorphic rocks. A mid-crustal conductive anomaly (C4) is related to the existence of interconnected fluids beneath the Central Range, coupled with a thermal effect. The existence of this conductive anomaly (C4) within the mid-crust supports the lithospheric collision tectonic model in southern Taiwan.

\section{ACKNOWLEDGEMENTS}

The authors acknowledge financial support from National Science Council of Taiwan. We would like to thank the National Chungcheng University (CCU) and Industrial Technology Research Institute (ITRI) for support the equipments and data collections. We greatly thank to both leaders of project TAIGER, Dr. F. T. Wu and Dr. C. Y. Wang suggested the TAIGER project and Dr. E. Turkoglu for helped at the fieldwork. We also thank to Dr. G. McNeice and Dr. A. Jones for provided their decomposition code.

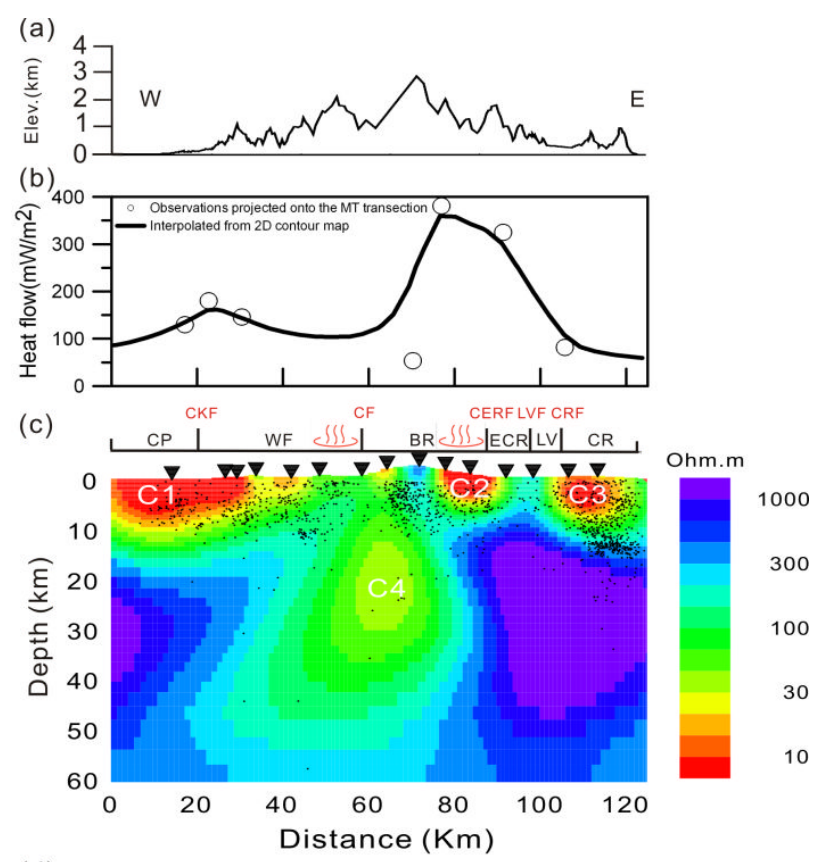

(d)

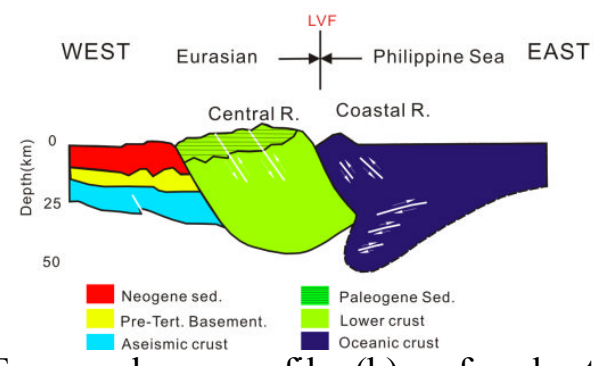

Figure 3 (a) Topography on profile, (b) surface heat flow variation profile (after Lee and Cheng, 1986). (c) The preferred 2D inversion model derived with $\tau=30$. Dots represent earthquakes $(\mathrm{M}>=3)$ located within $15 \mathrm{~km}$ of the MT profile. CP: Coastal Plan, WF: Western Foothill, BR: Backbone Range, ECR: Eastern Central Range, LV: Longitudinal Valley, CR: Coastal Range. CKF: Chuko Fault, CF: Chuichih Fault, CERF: Central Range Fault, LVF: Longitudinal Valley Fault, CRF: Costal Range Fault. (d) Schematic cross-section of the lithospheric model (modified from Wu et al., 1997).

\section{REFERENCES}

1) Chen, C. C., and Chen, C. S., 1998, Priliminary result of magnetotelluric sounding in the fold-thrust belt of 
Taiwan and possible detection of dehydration, Tectonophysics, 292, 101-127.

2) Egbert, G. D. and Booker, J. R., 1986, Robust estimation of geomagnetic transfer functions: Geophysical Journal of the Royal Astronomical Society, 87, 173-194.

3) Gamble, T. D., Goubau, W M. and Clarke, J., 1979, Magnetotellurics with a remote magnetic reference, Geophysics, 18, 605-635.

4) Hsu, T. L., 1956, Geology of the Costal Range, eastern Taiwan, Bull. Geol. Surv. Taiwan, 8, 39-63 (in Chinese).

5) Hsu, T. L., 1976, The Lichi mélange in the Coastal Range framework, Bull. Geol. Surv. Taiwan, 25, 87-95.

6) Ho, C. S., 1986, A synthesis of the geologic evolution of Taiwan. Tectonophysics, 125, 1-16.

7) Ho, C.S., 1999. An introduction to the geology of Taiwan explanatory text of the geologic map of Taiwan, Central Geol. Surv., Minist. Econ. Affairs, Taipei, Taiwan.

8) Jones, A. G., Chave, A. D., Egbert, G., Auld, D., and Bahr, K., 1989, A comparison of techniques for magnetotelluric response function estimation, $\mathrm{J}$. Geophys. Res. 94, 14201-14213.

9) Kao, H., Huang, G., and Liu, C., 2000, Transition from oblique subduction to collision in the northern Luzon arc-Taiwan region: Constraints from bathymetry and seismic observations, J. Geophys. Res., 105, 3059-3080.

10)Kim, K. H., J. Chiu, M., Pujol, J., Chen, K. C., Huang, B. S., Yeh, Y. H., and Shen P., 2005, Three-dimensional $\mathrm{Vp}$ and $\mathrm{Vs}$ structural model associated with the active subduction and collision tectonics in the Taiwan region, Geophys. J. Int., 162, 204- 220.

11)Lin, C.H., 2002, Active continental subduction and crustal exhumation: the Taiwan orogeny, Terra Nova, 14, 281-287.

12)McNeice, G.W., and Jones, A.G., 2001, Multisite, multifrequency tensor decomposition of magnetotelluric data. Geophysics, 66, 158-173.

13)Nesbitt, B., 1993. Electrical resistivities of crustal fluids: J. Geophys. Res. 98, 4301-4310.

14)Quist, A. S., and W. L. Marshall (1968), Electrical conductance of aqueous sodium chloride solution from 0 to $800{ }^{\circ} \mathrm{C}$ at pressure to 4000 bars, J. Phys. Chem., 72, 684-703.

15)Rodi, W. and Mackie, R. L., 2001, Nonlinear conjugate gradients algorithm for 2-D magnetotelluric inversion. Geophysics, 66, 174-187.

16)Seno, T., Stein, S., and Gripp, A. E., 1993, A model for the motion of the Philippine Sea plateconsistent with NUVEL-1 and geological data, J. Geophys. Res., 98, 17941-17948.

17) Soyer, W., Unsworth, M. J., 2006, Deep electrical structure of the northern Cascadia (British Columbia) subduction zone: Implications for the distribution of fluids, Geology, 34, 53-56, dot: 10.1130/G21951.1.

18) Suppe, J., 1981, Mechanics of mountain building and metamorphism in Taiwan: Geological Society of
China Memoir, 4, 67-89.

19) Sourirajan, S., and G. C. Kennedy, 1962, The system $\mathrm{H}_{2} \mathrm{O}-\mathrm{NaCl}$ at elevated temperature and pressures, Am. J. Sci., 260, 115-141.

20)Tsai, Y. B., 1986, Seismotectonics of Taiwan, Tectonophysics, 125, 17-38.

21)Unsworth, M., Soyer, W., Tuncer, V., Wagner, A., and Barnes, D., 2007, Hydrogeologic assessment of the Amchitka Island nuclear test site (Alaska) with magnetotellurics, Geophysics, 72, B47-B57.

22)Wang, Z., Zhao, D., Wang, J., and Kao, H., 2006, Tomographic evidence for the Eurasian lithosphere subducting beneath south Taiwan, Geophys. Res. Lett., 33, L18306, doi: 10.1029/2006GL027166.

23)Wu, F. T., Rau, R. J., and Salzberg, D., 1997, Taiwan orogeny: thin-skinned or lithospheric collision?, Tectonophysics, 274, 191-220.

24) Wu, F. T. and U.S./Taiwan TAIGER teams, 2007, TAIGER (TAiwan Integrated GEodynamics Reearch) project for testing models of Taiwan orogeny, Geophysical Research Abstracts, 9, 02135.

25) Wu, Y. W., C. H. Chang, L. Zhao, Shyu, J. B. H., Chen, Y. G., Sieh, K., and Avouac, J. P., 2007, Seismic tomography of Taiwan: Improved constraints from a dense network of strong motion stations, J. Geophys. Res., 112, B08312, doi: 10.1029/2007JB004983.

26) Wang, J. H., K. C. Chen, and T. Q. Lee (1994), Depth distribution of shallow earthquakes in Taiwan, J. Geol. Soc. China, 37, 125-142.

27)Wang, W. H., and W. J. Hung (2002), Synorogenic extension, Taiwan: Implications of physical and numerical modeling, Geol. Soc. Am., 358, 137-146. 